\title{
Transgender individuals represent an overlooked population amongst stem cell donors
}

\author{
Brian D. Adkins $\mathbb{( D}^{1} \cdot$ Bipin N. Savani ${ }^{2} \cdot$ Garrett S. Booth $\mathbb{( I D}^{1}$
}

Received: 19 December 2018 / Accepted: 22 December 2018 / Published online: 18 January 2019

(c) Springer Nature Limited 2019

Approximately 1-1.4 million Americans identify as transgender, a long overlooked and underserved patient population is in the United States [1-3]. Though reporting may underestimate the overall transgender population, the largest age group identifying as transgender is 18-24 years of life, which overlaps considerably with the population of hematopoietic stem cell donors, which tend to be younger individuals $[1,4]$. Therefore, considerations must be made for optimal practice in stem cell collection for transgender donors to ensure a safe and healthy collection.

A free language search of the current edition of the Foundation for the Accreditation of Cellular Therapy (FACT) Joint Accreditation Committee (JACIE) International Standards for Hematopoietic Cellular Therapy Product Collection, Processing, and Administration only has two standards relating to sex or gender [5]. Standard C6.5 requires retention of donor information related to gender along with other basic demographic information. This verbiage is vague and may lead to oversight on the part of the apheresis or transplant teams, which can be impactful as outcomes vary regarding relapse and graft versus host disease especially in female to male transplants $[6,7]$. This may also lead to unanticipated laboratory findings on karyotype and result in questions of specimen mix-up during clinical follow-up [8].

FACT JACIE standards B,C,CM 6.3.4 require a pregnancy test in all female donors within 7 days prior to mobilization, anesthesia, or preparatory regimen, which could lead to unnecessary donor distress or discomfort from

Brian D. Adkins

brian.adkins@ vanderbilt.edu

1 Pathology, Microbiology and Immunology, Vanderbilt University Medical Center, Nashville, TN, USA

2 Department of Internal Medicine, Division of Hematology and Oncology, Vanderbilt University Medical Center, Nashville, TN, USA unnecessary diagnostic laboratory testing, or alternatively not investigating pregnancy in individuals born female could be deleterious [9, 10].

Lapses in other accrediting bodies are also evident, the NMDP (National Marrow Donor Program) allows registration of all potential donors and specifies that a donor provide their sex as identified at birth. Though identifying LGBT needs has been recognized as a gap by the NMDP in the Patient-Centered Outcomes Research Agenda, their current standards provide no further guidance for caring for the transgender population [11]. Concurrently, FDA regulations relating to hematopoietic stem cells are regulated under 21 CFR 1271.3(d)(1) and Section 361 of the PHS Act and make no mention of gender or sex of donors.

By not including specific requirements based on gender, the transplant community as a result is somewhat inclusive. However, this is also a missed opportunity to provide compassionate and culturally competent care for these donors who represent an underserved population [3]. Though many of the above-mentioned assertions represent a worst-case scenario in terms of donor management, a lack of consideration for this emerging population may preclude donations and optimal management of these donors. Future regulations should include specific verbiage and guidelines relating to the transgender population.

\section{Compliance with ethical standards}

Conflict of interest The authors declare that they have no conflict of interest.

Publisher's note: Springer Nature remains neutral with regard to jurisdictional claims in published maps and institutional affiliations.

\section{References}

1. Flores AR, Herman JL, Gates GJ, Brown TNT. How many adults identify as transgender in the United States? The Williams Institute. 2016. https://williamsinstitute.law.ucla.edu/wp-content/uploa 
ds/How-Many-Adults-Identify-as-Transgender-in-the-United-Sta tes.pdf. Accessed 18 Dec 2018.

2. Meerwijk EL, Sevelius JM. Transgender population size in the United States: a meta-regression of population-based probability samples. Am J Public Health. 2017;107:2017.

3. Rice D, Smith S. Caring for a Transgender or Gender Nonconforming Patient - Articles Archive - Nursing Jobs, RN Jobs, Career Advice at Working Nurse. Work. Nurse. 2018. https://www. workingnurse.com/articles/Caring-for-a-Transgender-or-GenderNonconforming-Patient. Accessed 18 Dec 2018.

4. National Marrow Donor Program. Medical Guidelines for Donating Bone Marrow I Be The Match. 2018. https://bethematch. org/support-the-cause/donate-bone-marrow/join-the-marrowregistry/medical-guidelines/. Accessed 18 Dec 2018.

5. Foundation for the Accreditation of Cellular Therapy. Hematopoietic Cellular Therapy. 2018. https://www.ebmt.org/sites/defa ult/files/2018-06/FACT-JACIE7thEditionStandards.pdf.

6. Kongtim P, Di Stasi A, Rondon G, Chen J, Adekola K, Popat U, et al. Can a female donor for a male recipient decrease the relapse rate for patients with acute myeloid leukemia treated with allogeneic hematopoietic stem cell transplantation? Biol Blood Marrow Transplant. 2015;21:713-9.

7. Shin HB, Yoon J, Lee Y, Kim MS, Lee K. Comparison of malditof ms, housekeeping gene sequencing, and 16s rRNA gene sequencing for identification of Aeromonas clinical isolates. Yonsei Med J. 2015;56:550-555.

8. Chipkin SR, Kim F. Ten most important things to know about caring for transgender patients. Am J Med. 2017;130:1238-1245.

9. Maher JL, Mahabir RC. Preoperative pregnancy testing. Can J Plast Surg. 2012;20:32-34.

10. Roberts TK, Kraft CS, French D, Ji W, Wu AHB, Tangpricha V, et al. Interpreting laboratory results in transgender patients on hormone therapy. Am J Med. 2014;127:159-162.

11. Burns LJ, Abbetti B, Arnold SD, Bender J, Doughtie S, ElJawahiri A, et al. Engaging patients in setting a patient-centered outcomes research agenda in hematopoietic cell transplantation. Biol Blood Marrow Transpl. 2018;24:1111-1118. 